\section{Análise molecular da infecção natural de Lutzomyia longipalpis em área endêmica de leishmaniose visceral no Brasil}

\author{
Molecular analysis of natural infection of Lutzomyia \\ longipalpis in an endemic area for visceral \\ leishmaniasis in Brazil
}

\author{
1 Universidade Federal do \\ Piauí, Floriano, Brasil. \\ 2 Instituto de Doenças \\ Tropicais Natan Portela, \\ Teresina, Brasil. \\ 3 Universidade Federal do \\ Maranhão, São Luís, Brasil. \\ ${ }^{4}$ Centro de Pesquisas \\ Gonçalo Moniz, Fundação \\ Oswaldo Cruz, Salvador \\ Brasil. \\ Correspondência \\ M. R. A. Soares \\ Universidade Federal do Piauí. \\ BR-343, Km 3,5, Campus \\ Amílcar Ferreira Sobral, \\ Floriano, PI 64800-000, Brasil. \\ regianebiologia@yahoo.com.br
}

\begin{abstract}
The main purpose of this study was to investigate natural infection by Leishmania chagasi in female sand flies in a visceral leishmaniasis (VL) focus on São Luís Island, Maranhão State, Brazil. Molecular analysis by polymerase chain reaction (PCR) was applied to determine the rate of natural infection of Lutzomyia longipalpis by L. chagasi in areas of old and recent human settlement on São Luís Island. Based on a sample of $800 \mathrm{fe}$ male specimens captured from March to August 2005 , the natural infection rate was $1.25 \%$ in an area of old settlement and $0.25 \%$ in two recently settled areas. Infection of $\mathrm{L}$. longipalpis was detected in both areas, regardless of the number of reported human VL cases, indicating that other factors modulating infection in the wild need to be investigated. The results confirm PCR as a specific technique and an important tool for epidemiological surveillance.
\end{abstract}

Psychodidae; Leishmania; Polymerase Chain Reaction
Maria Regiane Araujo Soares 1,2 Cristiane Costa Carvalho ${ }^{3}$

Lucileine Amorim Silva 3 Mauro Sérgio Cruz Souza Lima ${ }^{1}$ Aldina Maria Prado Barral 4 José Manuel Macário Rebêlo ${ }^{3}$ Silma Regina Ferreira Pereira ${ }^{3}$

\section{Introdução}

Lutzomyia longipalpis (Diptera: Psychodidae) é o principal vetor da Leishmania infantum chagasi (Leishmania chagasi), agente etiológico da leishmaniose visceral (LV), uma das principais endemias mundiais e um grave problema de saúde pública no Brasil 1,2. Na ilha de São Luís, Maranhão, encontra-se em franca expansão, aliado à ampla distribuição geográfica do vetor e à alta prevalência da infecção canina 3,4 .

A determinação das taxas de infecção natural de flebotomíneos por Leishmania constitui uma importante ferramenta para os estudos epidemiológicos das leishmanioses e de competência vetorial. A técnica da dissecação do trato digestivo do vetor e a pesquisa direta do parasito eram empregadas com esta finalidade; atualmente, vem sendo substituída pela reação em cadeia da polimerase (PCR), que consiste na amplificação do DNA do parasito, exibindo elevada especificidade e sensibilidade 5 . Assim, iniciadores moleculares desenhados para L. infantum têm sido empregados para a detecção de L. chagasi, considerando a semelhança molecular e bioquímica entre essas espécies, reforçando a admissão da sinonímia L. infantum chagasi (L. chagasi) 1,6.

Este trabalho objetiva determinar a taxa de infecção natural de L. longipalpis por L. infantum chagasi, bem como associar a taxa de infecção à densidade vetorial. 


\section{Material e métodos}

\section{Áreas de estudo}

Foram selecionadas áreas de colonização antiga e recente situadas na ilha de São Luís (2³2'S e $44^{\circ} 43^{\prime} \mathrm{O}$ ), compreendendo os municípios de Raposa, São José de Ribamar, Paço do Lumiar e São Luís 7.

No momento do estudo, a área de colonização recente apresentava transmissão ativa de LV e cinco anos de ocupação, sendo constituída por dois aglomerados semi-urbanos do Município de Raposa (Vila Maresia e Residencial Thalita). Situa-se nas proximidades da praia, circundada por igarapés sob condições precárias de saneamento básico. A vegetação nativa cedeu espaço às habitações humanas, e o número de habitantes aproximava-se de 2.190 .

A área de colonização antiga (100 anos de ocupação) denomina-se Preiçueira. Situa-se na zona rural do Município de São José de Ribamar, com população estimada em 888 habitantes e indene quanto à transmissão de LV. Apresenta intensa cobertura vegetal, resguardando características nitidamente rurais e semi-rurais, com habitações isoladas e circundadas por plantações e árvores frutíferas ${ }^{8}$.

\section{Coletas de flebotomíneos}

Foram realizadas 22 coletas no período de março a agosto de 2005. Armadilhas luminosas do tipo CDC foram instaladas em abrigos de animais domésticos (galinheiros/poleiros, currais, pocilgas, apriscos e canil) das $18 \mathrm{~h}$ às $6 \mathrm{~h}$. Os flebotomíneos foram identificados taxonomicamente 9 , sendo as fêmeas de L. longipalpis agrupadas em lotes de dez espécimes (pools) e mantidas a $-20^{\circ} \mathrm{C}$ até a extração de DNA.

\section{Extração de DNA e PCR}

A extração de DNA foi realizada conforme Oliveira-Pereira et al. 10. Para a amplificação da região conservada do minicírculo, foram utilizados os primers RV1 (sense) e RV2 (antisense) específicos para L. infantum chagasi 11 . A reação foi realizada conforme Lachaud et al. 11 em MJ Research PTC100 (Peltier Thermal Cycler), tendo como controle negativo água ultrapura e controle positivo 186ng de DNA de L. chagasi (MHOM/BR2000/ MERZSTRAIN). Os produtos da PCR foram submetidos à eletroforese em gel de agarose a $2 \%$, sendo, posteriormente, fotodocumentados (Stratagene Eagle Eye II).

\section{Taxa de infecção natural mínima}

A taxa de infecção natural mínima foi calculada conforme Paiva et al. 5, e os resultados, analisados conforme o teste exato de Fischer (F) e o teste t de Student ( $\mathrm{p} \leq 0,05 ; \mathrm{n}-1$ graus de liberdade).

\section{Resultados}

Foram coletados 3.236 espécimes de L. longipalpis, sendo 2.426 machos e 800 fêmeas, separadas em 40 pools para cada área estudada (Tabela 1).

A população mínima de fêmeas de $L$. longipalpis apresentou uma prevalência de infecção de $20 \%$ e $30 \%$ por $L$. infantum chagasi para as áreas de colonização antiga e recente, respectivamente (Tabela 1). A taxa de infecção mínima foi de $1,25 \%$ para a área de colonização antiga (5 pools positivos) e $0,25 \%$ para a área de colonização recente (1 pool positivo). Os produtos de amplificação apresentaram um padrão de bandas de 145pb compatíveis com o controle positivo.

A análise estatística demonstrou que as diferenças encontradas entre o número de fêmeas, taxas de infecção e fêmeas potencialmente capazes de transmitirem $L$. infantum chagasi nas áreas estudadas não são significativas (Tabela 1).

\section{Discussão}

As taxas de infecção natural obtidas mostraramse próximas às detectadas por pesquisas anteriores 10,12. No momento do estudo, a área de colonização recente registrou três casos humanos de LV e, embora a área de colonização antiga não tenha registrado qualquer caso autóctone, ambas apresentam perfis endêmicos semelhantes 2 .

Em áreas endêmicas de leishmanioses, as taxas de infecção natural são consideravelmente baixas, não justificando a alta transmissão da doença, sobretudo em áreas de ocupação recente 12 . Com base nos dados estatísticos e na proporção de fêmeas infectadas para cada região, entendemos que as relações ecológicas, como habitat, comportamento intra-específico, ciclo de dieta e população de reservatórios de cada região, podem influenciar as taxas de infecção, ainda que os resultados demonstrados não sejam significativos estatisticamente. Sugerimos que as taxas de infecção natural detectadas e a manutenção da LV na ilha de São Luís estejam associadas à elevada prevalência da infecção canina nas áreas urbanas, à descontinuidade das estratégias de controle, além de fatores ambientais 13 , imunológicos 14 e genéticos 15 da população. 
Taxa de infecção natural de Lutzomyia longipalpis por Leishmania infantum chagasi em áreas de colonização antiga e recente na ilha de São Luís, Maranhão, Brasil.

\begin{tabular}{lcccc}
\hline Colonização & \multicolumn{2}{c}{ Número de espécimes } & Pools * & $\begin{array}{c}\text { Taxa infecção } \\
\text { mínima (\%) ** }\end{array}$ \\
& Macho & Fêmea & & 1,25 \\
Antiga & 1.509 & 400 & $35 / 5$ & 0,25 \\
Recente & 927 & 400 & $39 / 1$ & -
\end{tabular}

* Pools positivos;

** Fisher: 0,0295; Teste $t:=1,62 ; \mathrm{p} \leq 0,05 ; \mathrm{G}$. L: $\mathrm{n}-1$.

Nas localidades rurais, a dinâmica da ocupação dos espaços e o modo de vida da população contribuem para a formação de comunidades ecológicas estáveis, onde há a manutenção dos ecótopos naturais do vetor, dos reservatórios e do parasita. Tais características favorecem o ciclo de transmissão silvestre de Leishmania, sugerindo uma explicação para a ausência de casos humanos autóctones na área de colonização antiga. Por outro lado, modificações drásticas nas condições ambientais, causadas pela destruição de habitats, urbanização e a migração dos grupos populacionais, podem influenciar o ciclo de transmissão da doença pela desestabilização dos ecótopos naturais dos elos envolvidos na transmissão, favorecendo a aproximação desses elementos das populações humanas 13 .

Quanto aos fatores imunológicos, Kamhawi et al. ${ }^{16}$ e Teixeira et al. ${ }^{17}$ sugerem que a exposição a picadas de flebotomíneos não infectados pode influenciar na epidemiologia da doença. Os componentes presentes na saliva de flebotomíneos apresentam atividade imunogênica, induzindo à produção de anticorpos contra diferentes proteínas. Desta forma, animais expostos a picadas de flebotomíneos desenvolvem elevados níveis de anticorpos IgG anti-saliva, que podem interferir no risco em adquirir a infecção. Logo, populações humanas de áreas de colonização antiga que cohabitam com populações de L. longipalpis podem desenvolver proteção quanto à infecção por L. infantum chagasi, supondo a exposição destes indivíduos à picada do vetor.

É factível considerar que áreas de colonização recente, sobretudo ocupações irregulares, são instáveis, onde a proteção conferida pelos anticorpos pode ser menos expressiva por causa do intenso fluxo migratório, particularmente de pessoas suscetíveis vindo de áreas indenes. Nesse sentido, mesmo que a taxa de infecção e a densidade do vetor permaneçam baixas, são suficientes para manter a infecção circulando no meio urbano.

Em relação aos fatores genéticos, a variabilidade da resposta à infecção por Leishmania pode estar relacionada às características genéticas individuais. Polimorfismos no gene mbl2 têm sido pesquisados em diversas populações devido à sua importância na defesa do hospedeiro contra doenças infecciosas e autoimunes 15.

Nosso estudo demonstrou que a PCR foi capaz de detectar a infecção natural por L. infantum chagasi em populações de L. longipalpis, independentemente da existência de casos ativos de LV, revelando-se como um instrumento de grande importância para a saúde pública. 


\section{Resumo}

O objetivo deste estudo foi investigar a infecção natural por Leishmania chagasi em flebotomíneos capturados em focos de leishmanioses visceral (LV) na ilha de São Luís, Maranhão, Brasil. Análise molecular por reação em cadeia da polimerase (PCR) foi aplicada para determinar a taxa de infecção natural de Lutzomyia longipalpis por L. chagasi em áreas de ocupação humana antiga e recente, na ilha de São Luís. Valendo-se de uma amostra de 800 fêmeas coletadas no período de março a agosto de 2005, foi possível determinar taxas de infecção natural equivalentes a 1,25\% em uma localidade de colonização antiga e 0,25\% em duas localidades de colonização recente. A infecção foi detectada nas duas localidades independentemente do número de casos humanos de LV notificados, o que demonstra que outros elementos que modulam a infecção no meio natural precisam ser investigados. Os resultados obtidos confirmam a PCR como técnica específica e importante ferramenta para as ações em vigilância epidemiológica.

Psychodidae; Leishmania; Reação em Cadeia da Polimerase

\section{Colaboradores}

M. R. A. Soares participou da concepção do projeto, análise dos dados e redação do artigo. C. C. Carvalho contribuiu na análise dos dados e suporte técnico ao artigo. L. A. Silva deu contribuição científica ao artigo e revisão. M. S. C. S. Lima participou na análise estatística e revisão do artigo. A. M. P. Barral contribuiu na concepção do projeto e revisão do artigo. J. M. M. Rebêlo colaborou na concepção do projeto e revisão do artigo. S. R. F. Pereira participou na revisão do artigo.

\section{Agradecimentos}

Às comunidades de Vila Maresia, Thalita e Preçueira, pela receptividade e acolhida; a Jorge Moraes, pelo auxílio na identificação dos espécimes; a Maria Santana Viegas, pelo apoio em laboratório; ao Conselho Nacional de Desenvolvimento Científico e Tecnológico (CNPq; processo $n^{\circ}$. 620081/2004-0ACT) e à Fundação de Amparo a Pesquisa e ao Desenvolvimento Científico e Tecnológico do Maranhão, pela concessão de financiamento e bolsa de estudos.

\section{Referências}

1. Lainson R, Rangel EF. Lutzomyia longipalpis and the eco-epidemiology of American visceral leishmaniasis, with particular reference to Brazil - review. Mem Inst Oswaldo Cruz 2005; 100:811-27.

2. Ministério da Saúde. Manual de vigilância e controle da leishmaniose visceral. Brasília: Ministério da Saúde; 2004.

3. Silva AR, Tauil PL, Cavalcante MNS, Medeiros MN, Pires BN, Gonçalves EGR. Situação epidemiológica da leishmaniose visceral na ilha de São Luís, Estado do Maranhão. Rev Soc Bras Med Trop 2008; 41:358-64.

4. Rebelo JMM, Oliveira ST, Silva FS, Barros VLL, Costa JML. Flebótomos (Diptera: Psycodidae) da ilha de São Luís, zona do Golfão Maranhense. Rev Soc Bras Med Trop 1999; 33:247-53.

5. Paiva BR, Secundino NFC, Pimenta PFP, Galati EAB Andrade Júnior HF, Malafronte RS. Padronização de condições para detecção de DNA de Leishmania spp. em flebotomíneos (Diptera, Psychodidae) pela reação em cadeia da polimerase. Cad Saúde Pública 2007; 23:87-94.

6. Maurício IL, Stohard JR, Miles MA. The strange case of Leishmania (Leishmania) chagasi. Parasitol Today 2000; 16:188-9.

7. Instituto Brasileiro de Geografia e Estatística. Atlas do Estado do Maranhão. Rio de Janeiro: Instituto Brasileiro de Geografia e Estatística; 1984. 
8. Soares MRA. Distribuição de Lutzomyia longipalpis (Diptera: Psychodidae) e infecção natural por Leishmania chagasi na ilha de São Luís-MA, Brasil [Dissertação de Mestrado]. São Luís: Universidade Federal do Maranhão; 2006.

9. Young DC, Duncan MA. Guide to the identification and geographic distribution of Lutzomyia sand flies in Mexico, the West Indies, Central and South America (Diptera: Psichodidae). Gainesville: American Entomologic Institute; 1994.

10. Oliveira-Pereira YNO, Rebêlo JMM, Moraes JLP, Pereira SRF. Diagnóstico molecular da taxa de infecção natural de flebotomíneos (Psychodidae, Lutzomyia) por Leishmania sp. na Amazônia maranhense. Rev Soc Bras Med Trop 2006; 39:540-3.

11. Lachaud L, Marchergui-Hammami S, Chabbert E, Dereure J, Dedet JP, Bastien P. Comparison of six methods using peripheral blood for detection of canine visceral leishmaniasis. J Clin Microbiol 2002; 40:210-5.

12. Miranda JC, Reis E, Schriefer A, Gonçalves M, Reis MG, Carvalho L, et al. Frequency of infection of Lutzomyia phlebotomines with Leishmania braziliensis in a Brazilian endemic area as assessed by pinpoint capture and polymerase chain reation. Mem Inst Oswaldo Cruz 2002; 97:185-8.
13. Bejarano EE, Uribe S, Rojas W, Vélez ID. Phebotominae sand flies (Diptera: Psychodidae) associated with the appearence of urban leishmaniasis in the city of Sincelejo, Colombia. Mem Inst Oswaldo Cruz 2002; 97:645-7.

14. Barral A, Honda E, Caldas A, Costa J, Vinhas V, Rowton ED, et al. Human immune response to sand fly salivary gland antigens: a useful epidemiological marker? Am J Trop Med Hyg 2000; 62:740-5.

15. Nunes SPH. Polimorfismos no gene $m b l 2$ (lectina ligadora de manose) e suscetibilidade à leishmaniose visceral americana em região pré-amazônica, Brasil [Dissertação de Mestrado]. São Luís: Universidade Federal do Maranhão; 2006.

16. Kamhawi S, Yasmine B, Modi G, Rowton E, Sacks D. Protection against cutaneous leishmaniasis resulting from bites of uninfected sand flies. Science 2000; 5495:1351-4

17. Teixeira C, Gomes R, Barral-Netto M, Barral A, Brodskyn C. Influência da saliva de flebotomíneos na leishmaniose experimental e humana. Gazeta Médica da Bahia 2005; 75:18-23.

Recebido em 22/Mar/2010

Versão final reapresentada em 06/Jul/2010

Aprovado em 23/Ago/2010 